\title{
Apatite nanoresponse to acidic dissolution
}

\author{
NICOLAS PERDRIAL ${ }^{1}$, ROLAND HELLMANN ${ }^{2}$, ADELE \\ CONDE $^{1}$, ELIZABETH B. RAMPE ${ }^{3}$, ROY \\ CHRISTOFFERSEN $^{4}$, MITSUHIRO MURAYAMA ${ }^{5}$ AND \\ JERRY CHANG ${ }^{6}$
}

${ }^{1}$ University of Vermont

${ }^{2}$ ISTerre

${ }^{3}$ NASA Johnson Space Center

${ }^{4}$ Jacobs/NASA Johnson Space Center

${ }^{5}$ Virginia Tech

${ }^{6}$ University of Arizona

Presenting Author: nperdria@uvm.edu

Phosphorus uptake by plants and organisms is one of the most important life-sustaining processes occurring in the critical zone (CZ). Because 95\% of Earth's P reserves is relatively immobile in the form of apatite, plants and organisms rely on molecular scale solubilization process to extract available P. As the world experiences a global $\mathrm{P}$ shortage, influencing food production, it becomes increasingly important to understand apatite dissolution. The detailed study of chemically weathered apatite surfaces at the $\mu \mathrm{m}$ to $\mathrm{nm}$-scale is key to understanding $\mathrm{P}$ solubilization and uptake in the $\mathrm{CZ}$, allowing for better crop management and efficient fertilization.

Apatite weathering is generally viewed in terms of a $\mathrm{pH}$ dependent process where protons weaken atomic bonds, this leading to the disintegration of the apatite structure. A general feature of apatite weathering in acid and near neutral $\mathrm{pH}$ conditions is an apparent non-stoichiometric dissolution characterized by $[\mathrm{Ca} / \mathrm{P}] \mathrm{aq}>1.66$ in both fluorapatites $(\mathrm{FAP})$ and hydroxyapatites (HAP). This process leads to the formation of a surface altered layer (SAL) with a different composition from the bulk, which many have argued is a Ca-depleted "leached layer".

We investigated apatite weathering at the nanoscale using FIB-prepared TEM-foils. Our preliminary results based on laboratory-altered FAP at ambient $\mathrm{T}$ and $\mathrm{pH} 3$ show the formation of amorphous SALs with a maximum thickness of $\sim 10$ $\mathrm{nm}$. High resolution chemical mapping and profiling using STEM-EELS and STEM-EDXS indicate that the SALs are generally, but not always, depleted in $\mathrm{Ca}$ and enriched in $\mathrm{P}$. These results provide an alternate view of the mechanism of apatite dissolution with stoichiometric breakdown of the apatite structure, followed by the reprecipitation of an amorphous surface layer depleted in $\mathrm{Ca}$.

This mechanism can be described in terms of coupled interfacial dissolution-reprecipitation (CIDR), which is increasingly viewed as a universal mechanism of silicate mineral and glass dissolution. Our observation that apatite may dissolve similarly to silicates implies not only that apatite weathering may be more complex than originally thought, but also that the CIDR mechanism may extend beyond silicates. 